\title{
ANALYSIS OF THE PERIODIC BREATHING OF A TRANSVERSE ANNULAR CRACK PROPAGATED IN A REAL ROTATING MACHINE
}

\author{
S. Chatterton, P. Pennacchi, A. Vania, P. Rubio* \\ Politecnico di Milano, Dept. of Mechanical Engineering \\ *Universidad Carlos III de Madrid
}

Keywords: transverse annular crack, breathing mechanism, model-based simulation, finite element model

\begin{abstract}
This paper shows the numerical results of a model-based analysis carried out to investigate the experimental dynamic behaviour of the shaft of a real steam turbine in which a deep annular - or circumferential - crack propagated. The shape of this transverse crack was caused by the generation of multiple initiation points, equally spaced over the whole circumferential surface of the shaft cross-section located at the first high pressure stage of the steam turbine.

The periodic breathing of the crack caused changes in the area moments of inertia of the damaged crosssection and fault symptoms. Conversely, the shaft heating that affected the turbine during the load rises performed at the end of the runups carried out from a cold state pointed out an abnormal sensitivity of the synchronous vibrations to the machine thermal state. As a result, the fault symptoms caused by this crack were quite different from those induced by common shaft transverse cracks. The breathing of this crack, caused by gravity, has been studied by means of a mathematical model in order to investigate the influence of the crack opening and closure on the harmonic content of the turbine vibration.

A new approach is used in this paper, considering a more appropriate 3D FE model that allowed the nonlinear distribution of the stresses in the cracked section to be estimated. The method used for the present study has proved that the non-linear distribution of the axial stresses in the area close to the crack tip gives only minor effects on the breathing mechanism. This is an original contribution, which could have not been observed in previous authors' papers that employed simplified models for the periodic breathing.

The good accordance between numerical results and experimental data confirms the adequacy of the investigation method used for this study. With reference to diagnostic purposes, this involves that the early on-line detection of annular cracks propagated in the shafts of rotating machinery needs to use more accurate techniques, based on the analysis of vibration data, which can point out fault symptoms, even in the case of very deep transverse cracks.
\end{abstract}

\section{INTRODUCTION}

Shaft crack propagations are one of the most serious faults in rotating machines for power generation [1]. Fortunately, they do not occur as frequently as other common faults such as shaft imbalances, rubs, machinetrain misalignments and shaft thermal bows. However, the consequent maintenance actions may be very expensive as shaft repairs can be sometimes carried out only in case of a prompt detection of a crack in the early stage of its initiation. This might only be obtained by means of Non Destructive Tests (NDT), that is Ultrasonic Tests (UT) or Dye Penetrant Inspections (DPI) performed during a preventive planned maintenance [2]. Conversely, if the symptoms of a shaft crack are not detected, its propagation can cause severe damage and even a catastrophic yielding of the shaft [3]. In this worst case, considerable secondary faults may occur, with possible high risk of injuries for the plant personnel. Therefore, the costs of the machine substitution, those of repair of induced damage, along with the cost of a long outage of the plant can be noticeable.

The on-line detection of shaft crack propagations can be performed during normal operating conditions by means of diagnostic methods based on a continuous monitoring of the rotating machine vibration [4]. The symptoms of this fault mainly depend on the crack shape and depth, as well as on the axial position of the cracked section of the rotor [5]. Unfortunately, these symptoms may not be very evident until the crack depth has already reached rather high values in comparison to the shaft radius.

In horizontal machine-trains, the phenomenon of the periodic closure and opening of shaft transverse cracks, caused by gravity, which occurs during a full revolution of the rotor, generates uncommon dynamic periodic forces that affect the machine vibration [6],[7],[8],[9]. Common shaft transverse cracks, having an elliptical front, usually cause major changes in the synchronous (1X) and twice per revolution (2X) harmonic components of the shaft vibration. Minor changes may also affect further super-synchronous harmonic 
orders. However, these changes in the machine dynamic behaviour can be also ascribed to some other faults and malfunctions that commonly affect rotating machines. Some changes of the same harmonic orders of the system vibration can be even caused, in healthy machines, by changes in the shaft thermal state and in process parameters that occur in normal operating conditions.

More significant fault symptoms can be detected during speed transients. In fact, the periodic closure and opening of the crack, often called crack breathing [10],[11] causes $2 \mathrm{X}$ forces that excite the balance resonance of the shaft when the machine rotational speed approaches half of the value of the corresponding first flexural critical speed. This phenomenon causes an amplification of the $2 X$ vibration levels of the shaft. Usually, the peak magnitude of this $2 \mathrm{X}$ resonance, which is affected by the crack depth, is not very high. However, the occurrence of this phenomenon is unexpected in healthy shafts whose cross-section is full circular, that is axial-symmetric. This is a common geometrical characteristic of most shafts in rotating machines. Therefore, abnormal values of the $2 \mathrm{X}$ vibration of a rotor is often considered a possible warning symptom of the presence of a shaft crack. However, some crack shapes may cause more ambiguous fault symptoms that make the early detection of a crack propagation rather difficult. For instance, the peculiar effects of helical cracks have been analysed in the literature, while some other papers describes the effects of the so-called circumferential crack or annular crack [2],[12],[13].

This paper shows the results obtained with a model-based investigation method that has been applied to analyse the experimental dynamic behaviour of the shaft of a real steam turbine in which a deep annular crack propagated [2],[14],[15],[16]. The model is based on a finite beam element model (FE) of the turbine shaft coupled with a three-dimensional, 3D, finite element model of only a short part of the shaft in correspondence of the cracked section.

Owing to the peculiar shape of the crack its periodic breathing caused only minor changes in the $2 \mathrm{X}$ vibration. Conversely, the $1 \mathrm{X}$ vibration measured in operating condition showed an abnormal sensitivity to the machine thermal state, especially during the turbine heating from a cold state. This sensitivity increased more and more in the time, along with the increasing number of the machine runups and consequent thermal transients. As a result, it was decided to remove the turbine from the machine-train of the power unit.

A detailed inspection, carried out in a workshop, allowed detecting a deep transverse annular crack. The damage propagated in radial direction from multiple initiation points located over the whole circumferential surface.

Some experimental evidences of this fault are shown in the paper along with the results of a model-based analysis that has been performed to study the periodic breathing of this uncommon shape of shaft transverse cracks. In particular, the periodic changes of the second moments of area of the cracked section have been evaluated. The numerical results obtained with this analysis have been used as input data for a further investigation focused on the simulation of the periodic changes in the static bending of the cracked shaft caused by a complete revolution of rotor. The numerical results of this study have been compared to the dial gauges readings collected during a specific test performed in the workshop in which the turbine shaft has been rotated manually.

The good accordance between experimental data and numerical results confirms the adequacy of the investigation method used for this study.

\section{CASE STUDY}

Demand response rules that allow electric utilities to better match the demand for power with the supply have been subjected to significant changes, in European liberalized markets, over the last two decades. This has considerably influenced the way with which power units are operated, especially in the case of small units whose rated power is lower than about $200 \mathrm{MW}$. Owing to this, many power units are subjected to weekly and even daily start-ups and coast-downs. This can involve an increase of machine faults that might be due, for instance, by the increasing number of events of high vibration levels caused by passing through flexural and torsional critical speeds of the rotors.

Besides, high-pressure (HP) steam turbines are also affected by a further serious problem. In fact, these machines are subjected to considerable thermal transients that occur during the first load rise carried out at the end of each runup. The most critical condition occurs when the turbine is started-up from a cold thermal state. Both rotor and machine case are subjected to an important heating, in the direction of the longitudinal axis, caused by the steam flow through the various turbine stages. However, a further considerable thermal transient also occurs in radial direction, owing to the difference between the initial temperature of the shaft core, which nearly coincides with the "room temperature", and the noticeable temperature of the steam flow that licks the external surface of the shaft. This last phenomenon is particularly important at the first stage of 
HP turbines. Very high mechanical stresses can be generated in the rotor by these thermal transients that can last about half an hour, or a longer time, depending on shaft radius and steam flow characteristics.

As said above, the experimental behaviour of a steam turbine installed in a $177 \mathrm{MW}$ combined cycle power plant has been investigated. The power unit was composed of an industrial gas turbine, a generator and a $63 \mathrm{MW}$ condensing-type steam turbine that was connected to the remaining part of the machine-train by means of a synchronous self-shifting clutch. The rated speed of the unit was $3000 \mathrm{rpm}$.

The steam turbine rotor was machined from a solid forging of alloy steel. Fifty-four bladed disks were mounted on the turbine shaft. The first twenty-seven of them were the high-pressure stages (HP).

The rotor was supported by two five shoes tilting-pad journal bearings in load-on-pad configuration (LOP). The front-end pedestal of the HP casing contained the thrust bearing. Each journal bearing was equipped with a pair of XY proximity probes mounted 90 degrees apart. Figure 1 shows the steam turbine layout and the journal bearing numbering. Bearings \#1 and \#2 were located at the non-drive end (NDE) and at the drive end (DE), respectively.

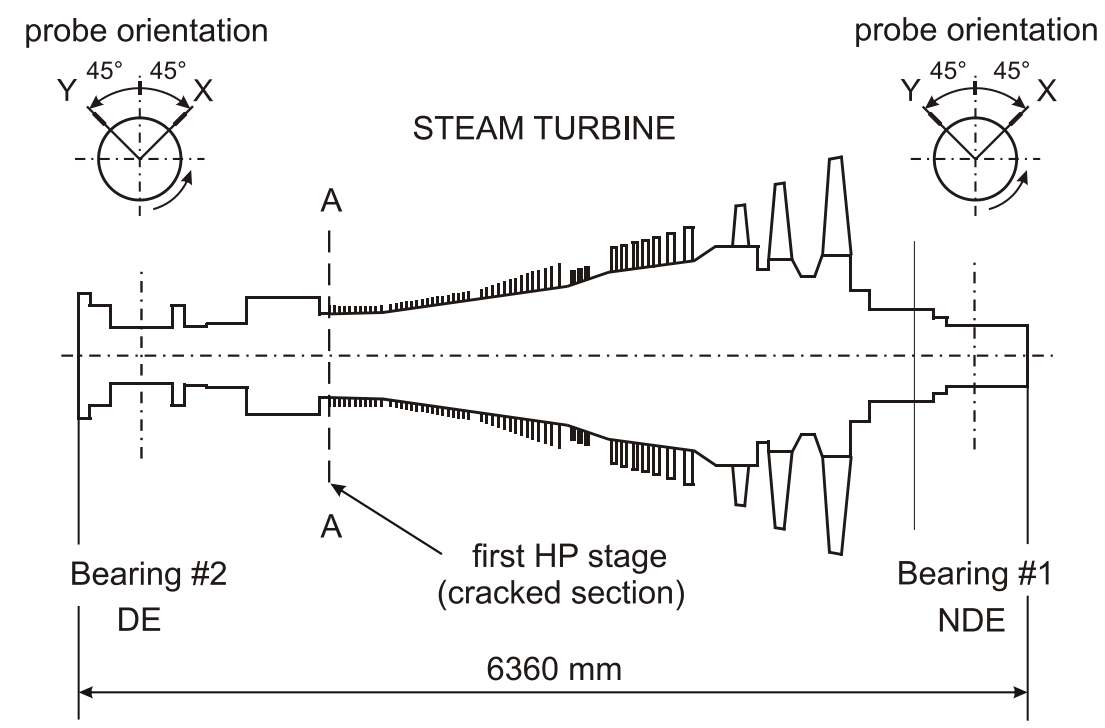

Figure 1. Steam turbine configuration

The case history described in this paper occurred after the turbine had worked for about 72000 hours in on-load operating condition, during ten years of service.

The steam turbine had been subjected to 118 starts over the last ten years and even to 89 further starts over the last half a year, carried out after the last planned overhaul. The large number of starts occurred in the last six months was caused by the new rules of the demand response. In fact, the small size of this unit allowed it to ramp quickly enough to operate in the new electric market. However, frequent starts and stops cause an increased number of passing through the rotor balance resonance and severe thermal shocks in the turbine shaft. This can contribute to the initiation of shaft cracks. With reference to this risk, the most critical part of the turbine is the external surface in the area close to the first HP stages.

At first, the synchronous (1X) vibration data collected in on-load operating conditions started showing an abnormal behaviour. Amplitude and phase of the 1X harmonic component of the shaft vibration seemed to be influenced by the machine thermal state. This sensitivity to the rotor temperature, which was more important during the machine thermal transients, increased in time, over a few months. However, the magnitude of the corresponding $2 \mathrm{X}$ vibration level was very low and nearly unaffected by the turbine thermal state [16],[17]. The amplitude of the twice per revolution vibration measured in operating condition ranged from 5 to $9 \mu \mathrm{m}$ pp (peak-to-peak).

Figure 2 and Figure 3 show the amplitude of the $1 X$ and $2 X$ vibration, respectively, measured at the inboard bearing of the rotor, in the $\mathrm{X}$ direction, during a machine runup carried out with an initial cold thermal state. In order to better point out the dynamic effects occurred when the rotational speed passed through the half critical speed and the first balance resonance of the turbine shaft, the $2 \mathrm{X}$ vibration vectors shown in Figure 3 have been compensated by subtracting the corresponding $2 \mathrm{X}$ slow-roll runout vector.

After the turbine has been started up, a speed dwell was carried out at $800 \mathrm{rpm}$ in order to obtain a stabilization in the machine differential thermal expansion. After having kept the rotational speed at a 
constant value for about seventy-five minutes, the runup has been completed. The trend of the turbine rotational speed during this runup is shown in Figure 4.

In the long-time period during which the rotational speed was kept constant the weak but hot steam flow caused a continuous heating of the turbine shaft. This gave rise to an important thermal gradient both in radial and axial direction. As a result, the shaft crack, which had not been detected yet, was affected by a partial closure that caused a decrease of the $1 \mathrm{X}$ vibration amplitude. This is the reason for the drop down of the vibration level shown in Figure 2, in the speed range close to $800 \mathrm{rpm}$.

In fact, during the turbine heating the temperature of the rotor surface was significantly higher than that of the shaft core. Owing to the radial gradient of temperature, the inner area of the rotor, close to the longitudinal axis, is subjected to tensile stresses, while compressive stresses are generated in the shaft area close to the external surface. This causes a partial closure of shaft transverse cracks, which commonly propagate from the circumferential external surface of the rotor.

Figure 2 shows that during the remaining part of the runup the $1 \mathrm{X}$ vibration amplitude is rather low. Conversely, the amplitude of the $1 \mathrm{X}$ vibration measured at the inboard bearing $\# 2$ at the beginning of the speed ramp is not very low. This indicates that the turbine shaft, whose initial thermal state was cold, was affected by a not negligible eccentricity, although the machine had been operated in barring mode for many hours before the runup.

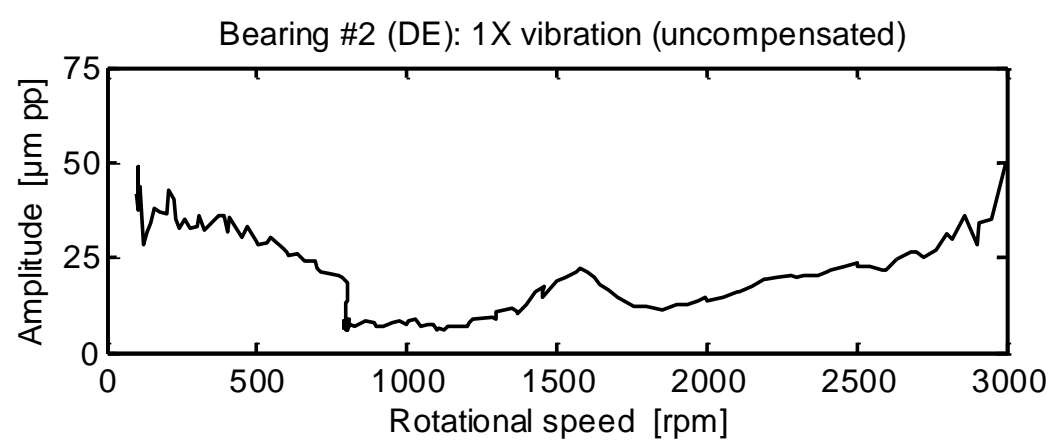

Figure 2. Amplitude of the $1 \mathrm{X}$ uncompensated vibration measured at the inboard bearing \#2 during a cold runup

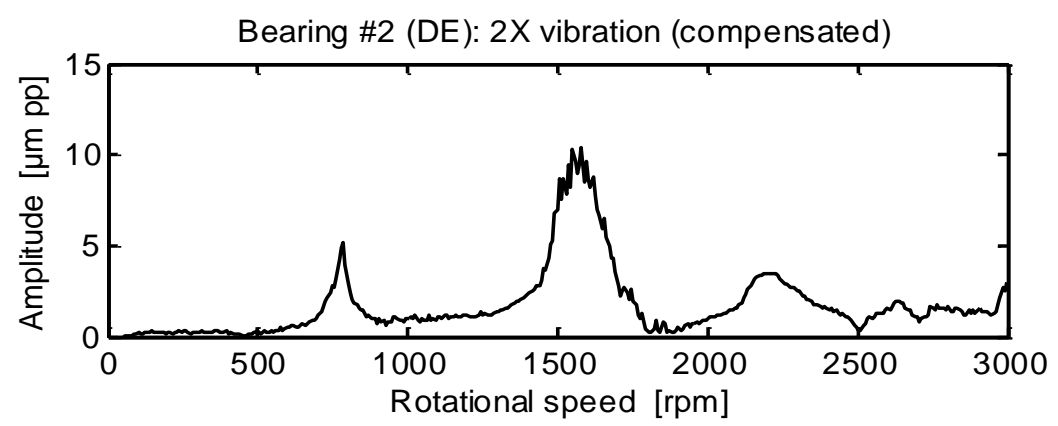

Figure 3. Amplitude of the $2 X$ compensated vibration measured at the inboard bearing \#2 during a cold runup

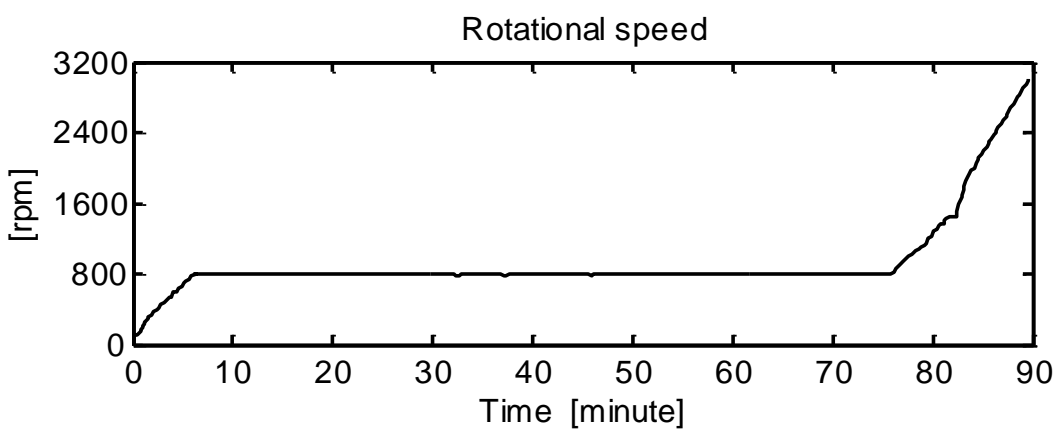

Figure 4. Trend of the turbine rotational speed measured during a cold runup 
The amplitude of the $2 \mathrm{X}$ vibration measured at the rated speed, at the end of this runup, is rather low. This amplitude was only affected by negligible changes in the on-load operating condition, even during the considerable heating suffered by the steam turbine as a consequence of the first load rise carried out after the runup [16],[17]. However, the level of the $2 \mathrm{X}$ vibration is affected by a small but evident amplification when the rotational speed reached $775 \mathrm{rpm}$. This phenomenon occurred when the rotational speed approached half the first flexural critical speed of the turbine shaft, which is about $1580 \mathrm{rpm}$. This symptom strengthened the suspect of a shaft crack propagation because this turbine rotor should be commonly affected by negligible $2 \mathrm{X}$ excitations, mainly caused by possible nonlinear effects in the oil-film journal bearings.

Therefore, the turbine shaft was removed from the machine-train of the unit and it was transported to a workshop for detailed inspections. The rotor was mounted on two rigid supports located at the shaft journals. Then, an impact test was performed by applying an impulse excitation to the shaft, in vertical direction, in an area rather close to the first HP stage. The system response was measured with an accelerometer mounted on a cross-section of the shaft fairly close to the excitation point. Multiple impact tests were performed by changing the angular position of the shaft, with an angular step of $45^{\circ}$ degrees, over a full revolution. These rotations of the shaft were carried out manually.

These tests showed that the first natural frequency of the turbine rotor depended on its angular position. Moreover, this natural frequency was affected by a periodic change whose maximum magnitude was about $1 \mathrm{~Hz}$ [16]. The findings obtained with further impact tests, performed with the same procedure, showed that these results were repetitive. This confirmed the suspect that a shaft crack had propagated in a cross-section of the turbine close to the first HP stage.

Unfortunately, the blades of the first $27 \mathrm{HP}$ stages could not be removed without destroying them, owing to the manner with which they had been fixed to the rotor. Therefore, the blades of all the HP stages have been machined in order to allow the shaft surface to become accessible for NDT and visual inspections.

Figure 5 shows the turbine shaft after having removed the blades of these stages. An evident crack was found at the bottom of the slot of the first HP stage where the blade roots were mounted. The thickness of the crack was so large that a simple visual inspection was sufficient to detect it. Besides, the crack was extended all over the circumferential surface of the shaft, at the bottom of the slot. Figure 6 shows an enlargement of the circumferential view of the crack.

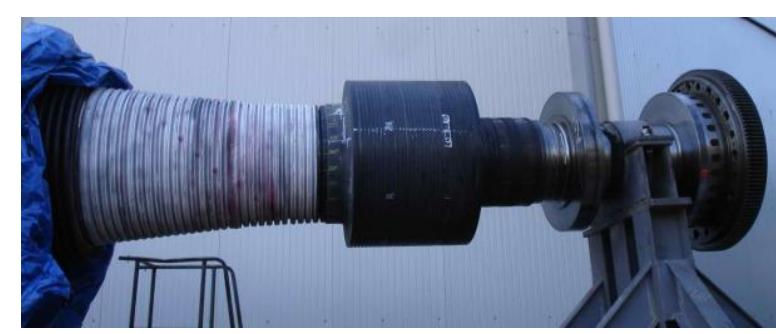

Figure 5. Turbine shaft after having removed the blades of the first $27 \mathrm{HP}$ stages

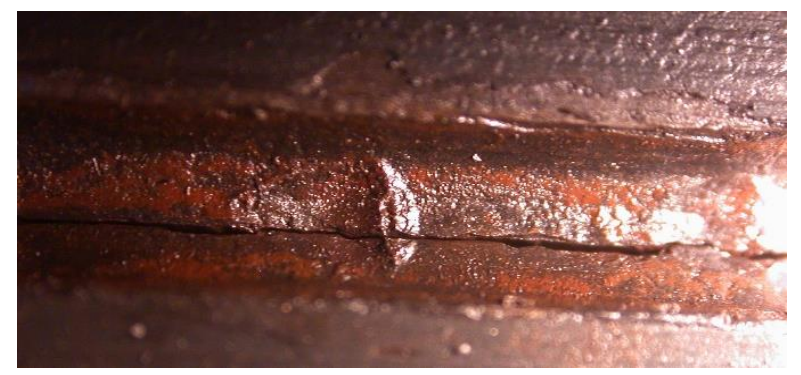

Figure 6. Enlargement of the circumferential view of the crack

The longitudinal section view illustrated in Figure 7 shows the shape of the blade root and the corresponding slot, along with the position of the crack propagation. A pin mounted at the bottom of the slot, with a shrink-fitting assembly, allowed fixing the blade root to the rotor.

Later on, the crack was opened in order to perform more detailed investigations. This needed to cut the shaft at two cross-sections located at opposite sides of the damaged area of the rotor, that is before the balance piston and beyond the last HP stage. Then, this shaft stub was cut into two parts along a diametrical plane. Finally, a static load was applied to the two halves of this stub in order to open the transverse crack of the shaft. 


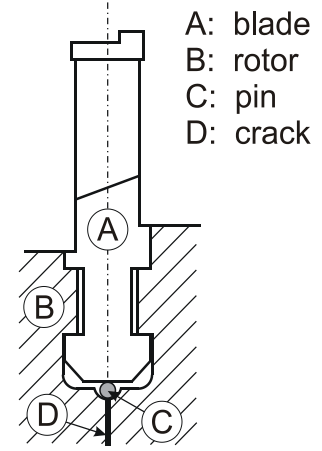

Figure 7. Longitudinal sectional view of the dovetail slot and the blade root of the 1st HP stage

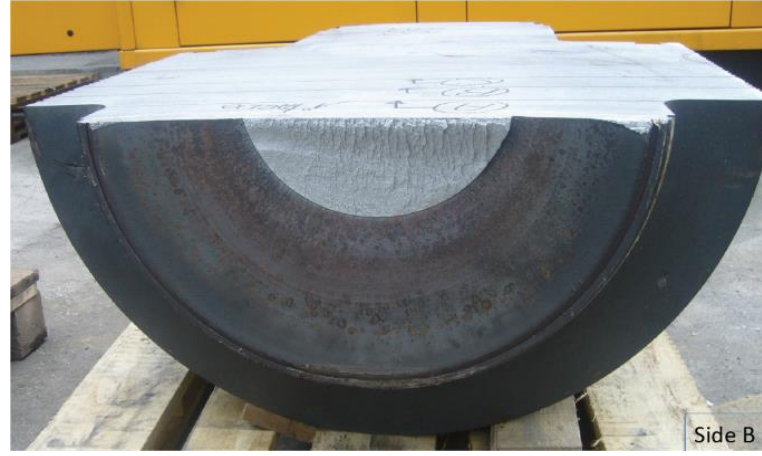

Figure 8. Front view of one of two halves of the cracked shaft

Figure 8 shows a front view of one of these parts of the shaft that contains the crack surface. The large depth of the crack is really evident. In the end, a thin slice of the shaft was cut from the two specimens, on the same side of the crack. Figure 9 shows a complete front view of the cracked section of the shaft. The specimens mentioned above were used to perform fractographic and metallographic investigations whose results are summarised in [2].

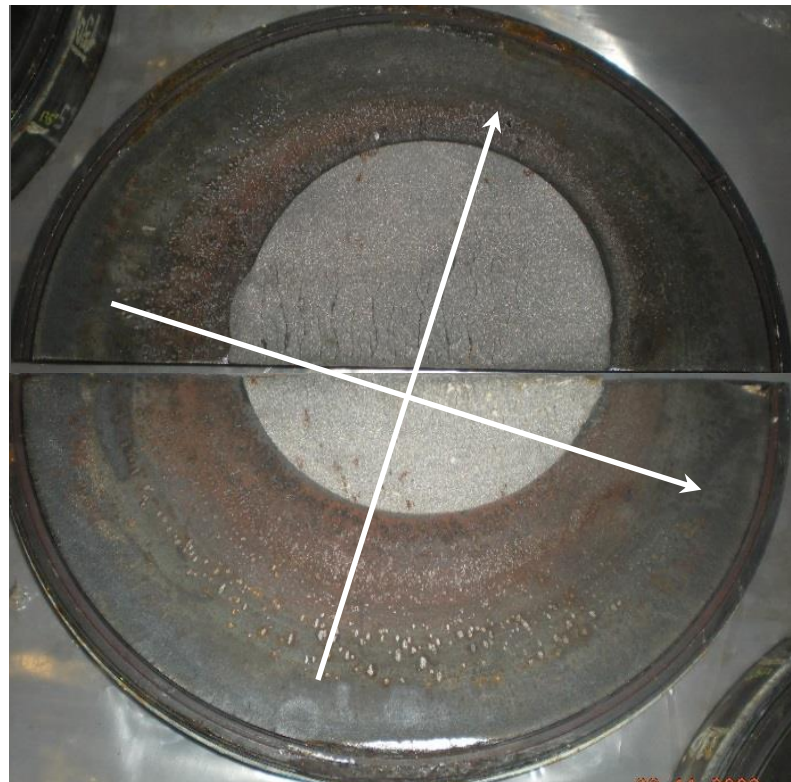

Figure 9. Front view of the complete cracked section of the shaft

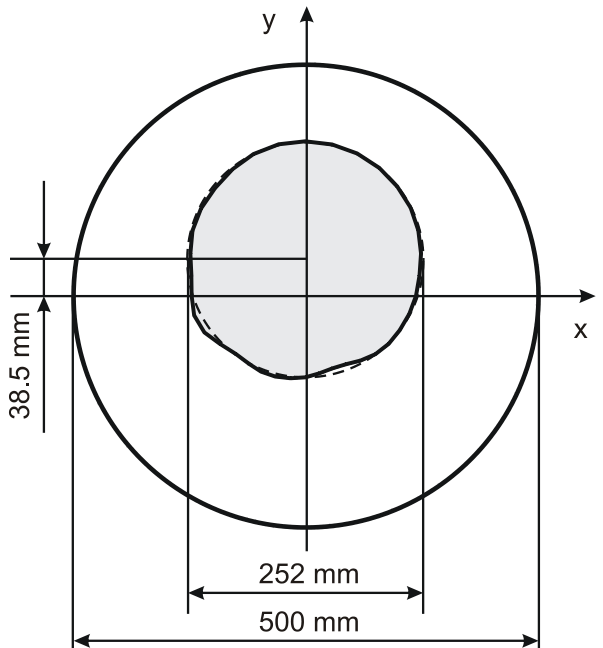

Figure 10. Geometrical parameters of the cracked section

The residual resistant section of the shaft is very small and nearly circular shaped. Besides, it is eccentric with respect to the centre of the original section of the shaft, whose diameter, measured at the bottom of the dovetail slots, is $500 \mathrm{~mm}$. The radius of the circle that fits the crack front is $126 \mathrm{~mm}$, while the eccentricity of the residual section of the rotor is about $38 \mathrm{~mm}$ (Figure 10). Therefore, the area of the residual section is about a quarter of the original section of the shaft.

Some authors call this kind of shaft cracks "circumferential cracks", however most shaft transverse cracks are extended over a partial arc of the external surface. Conversely, the crack shown in Figure 9 is extended over the complete circumferential surface. Therefore, in order to avoid any misunderstanding, the authors of the present paper prefer to call it as "annular crack" (or "full circumferential crack").

Some evidences pointed out by the metallographic analysis have shown that the rotor was rather close to a possible final catastrophic yielding [3].

Figure 11 shows an enlarged view of the cracked section in the proximity of the external surface of the shaft. It is possible to note the presence of multiple initiation points of the crack. This confirmed the suspect that excessive mechanical stresses, likely generated by the recurrent thermal transients suffered by the steam turbine, caused the propagation of the crack, in the radial direction, starting from the root of most of the 
blades of the first HP stage. This diagnosis is in accordance with the large number of start-ups of this turbine that had occurred during the last six months of machine service.

Table 1 shows the magnitude of the $1 \mathrm{X}$ slow-roll vectors measured close to bearing \#2, with the machine operating on turning gear, in a cold thermal state. These monitoring data, which represent a measure of the shaft eccentricity, were collected after four coast-downs carried out during a period of about six months during which some long outages occurred. The data contained in Tab. 1 show that the magnitude of the shaft eccentricity increased over time, significantly, as a consequence of the crack propagation.

Table 1. Evolution over time of the shaft eccentricity measured on turning gear

\begin{tabular}{|c|c|}
\hline DATE & $\begin{array}{c}\text { SHAFT } \\
\text { ECCENTRICITY }\end{array}$ \\
\hline 01.15 .2009 & $20 \mu \mathrm{m}$ \\
\hline 01.19 .2009 & $26 \mu \mathrm{m}$ \\
\hline 01.24 .2009 & $37 \mu \mathrm{m}$ \\
\hline 03.05 .2009 & $42 \mu \mathrm{m}$ \\
\hline 07.29 .2009 & $45 \mu \mathrm{m}$ \\
\hline
\end{tabular}

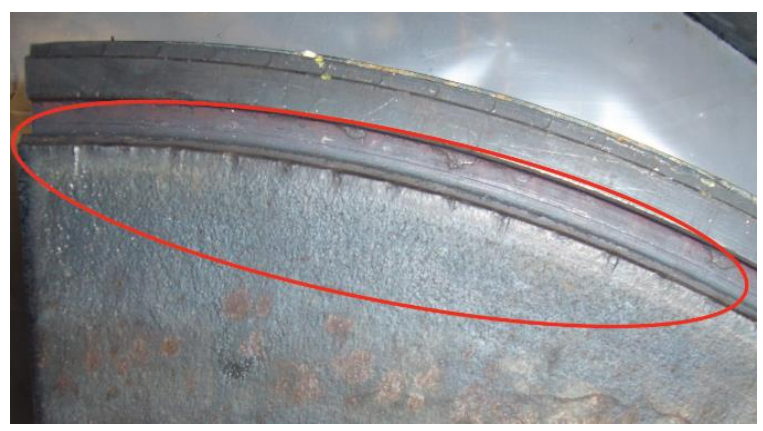

Figure 11. Multiple initiation points of the crack

\section{CRACK BREATHING}

The rotor weight generates bending moments in the cross-sections of the shafts of horizontal rotating machines. In case of cracked shafts these bending moments cause a periodic closure and opening of transverse cracks over a full revolution of the rotor. This phenomenon, which is often called crack breathing, allows the opposite surfaces of ideal thin planar transverse cracks to come in contact in the area of the cracked section that is subjected to compressive axial stresses. Therefore, compressive axial stresses can be transmitted across the two parts of the shaft that are located at the opposite sides of the cracked section also through a limited area of the crack surfaces. Shape and extension of the area of the crack surfaces that come in contact under the effect of compressive stresses change during a shaft revolution as they depend on the angular position of the rotor. That is on the angular position of the crack with respect to the vertical axis, along which the gravity force acts. In accordance with the above-mentioned assumption, the area of the crack surfaces that is virtually subjected to tensile axial stresses is unable to transmit any stress to the opposite part of the shaft. Therefore, the crack surfaces are not in contact in this part of the cracked section. Conversely, tensile stresses can be only transmitted through the residual resistant section of the shaft.

For a given angular position of the rotor, the actual resistant section of the cracked shaft can be defined as the combination of the residual resistant section and the closed area of the crack.

In a real case, the thickness of a transverse crack may be not negligible in the area far from the tip. Therefore, the axial displacements induced by the rotor weight, which tend to close the crack, might be not sufficient to cause the contact between the opposite surfaces of the crack. If the crack surfaces are not planar or they are subjected to oxidation, the distribution of the contact points on the crack surfaces can be more complex. As said above, an ideal thin planar crack has been considered in this investigation.

The continuous rotation of a horizontal cracked shaft causes a periodic change in the distribution of the axial stresses in the cracked section and then a periodic closure and opening of the crack. 
Because of the crack breathing, the local flexural stiffness of a cracked shaft depends on the actual area of the cracked section that can transmit compressive and tensile axial stresses. Therefore, this local flexural stiffness is affected by the periodic changes of the second moments of area of the actual resistant section of the shaft. Because of the periodic changes in the angular position of the principal axes of the actual area of the cracked section, a complex bending of the shaft can be generated during the complete revolution of the rotor.

Under the assumption that the nonlinear phenomena only cause minor effects in the machine response, the harmonic orders of the Fourier Series into which the periodic second moments of area of the actual resistant section can be decomposed affect the corresponding harmonic orders of the machine vibration. As a consequence of the most common shapes of shaft transverse cracks, the most important effects in the dynamic behaviour of the shaft are changes in the synchronous (1X) and twice per revolution (2X) vibrations. Very deep cracks, as well as important nonlinear effects, may also cause significant changes in higher order harmonic components. Since many healthy rotating machines are commonly affected by negligible $2 \mathrm{X}$ vibrations, the appearance and a continuous change of this harmonic order is often considered the most important symptom of a shaft crack propagation. However, even a preliminary qualitative prediction of the crack behaviour allows one to suppose that, because of its shape, the breathing of the crack shown in Figure 9 may mainly cause 1X changes in the second moments of area of the actual resistant section. Owing to this, the common symptom that allows a shaft crack to be detected by means of the on-line analysis of the machine vibration measured in operating condition may be really negligible. This was confirmed by the experimental findings.

A model-based analysis has been carried out in order to study the breathing phenomenon of such a crack in order to evaluate the sensitivity of the $2 \mathrm{X}$ vibration to radius and eccentricity of the residual circular section. The results of this investigation can be very useful to improve diagnostic methods focused on the early detection of shaft cracks, based on the analysis of vibration monitoring data collected in operating condition and rotational speed transients.

Some parametric analyses, based on simplified methods, have been performed by the authors in the past [14],[15]. Despite the approximations of the numerical techniques that have been used in those investigations, satisfactory results have been obtained. Conversely, a more accurate approach based on a significant improvement of the model, has been used in the study described in the present paper.

The crack breathing can be also influenced by the dynamic effects caused by the shaft rotational speed and the consequent vibrations induced, for instance, by machine misalignments and the common residual imbalance of the rotors. However, these dynamic effects often cause only a negligible contribution to the periodic closure and opening of transverse cracks of heavy horizontal shafts. Therefore, these effects have not been taken into account in the present study.

A preliminary finite element model (FE) of the turbine shaft has been generated (Figure 12). In accordance with common methods used to investigate the dynamic behaviour of rotating machines, this model is only composed of beam finite elements whose geometrical and mechanical characteristics allow the flexural and torsional stiffness of the shaft as well as its inertia properties to be simulated [19],[20]. Rigid journal bearings and pedestals have been included in the model.

Then, two cross-sections of the shaft located at opposite sides of the cracked section, not very far from it, have been considered. These cross-sections are denoted A and B in Figure 12. This model has been used to evaluate the bending moments and shear forces acting at these cross-sections, caused by the rotor weight. The effects of machine thermal transients have been neglected in this study.

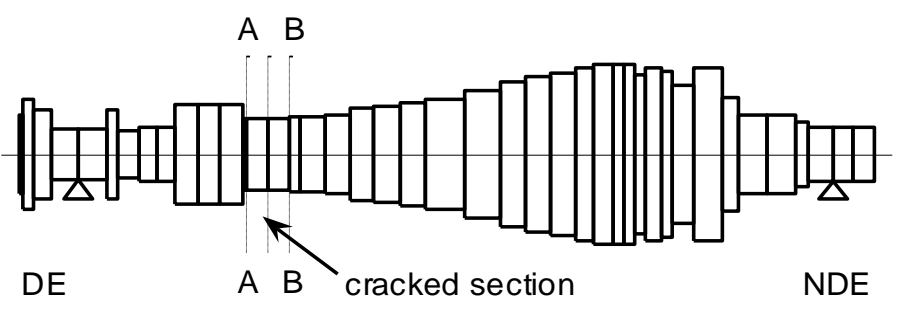

Figure 12. Simplified finite element model of the turbine shaft

Afterwards, in order to reduce the computational time taken by the study of the crack breathing mechanism, a more accurate three-dimensional, 3D, finite element model of only a short part of the shaft 
delimited by the cross-sections A and B has been generated using the commercial code ABAQUS (Figure 13 (a)). The length of this part of the rotor is $L=282 \mathrm{~mm}$, whereas the diameter at the cracked section is $D=$ $520 \mathrm{~mm}$. This diameter is only a little larger than that evaluated at the bottom of the dovetail slot of the first HP stage.

The transverse crack of the real rotor has been included in the model in correspondence of the actual cross-section. The front (profile) of the full annular crack has been assumed to be circular: this is in a good accordance with the experimental findings. The actual eccentricity of the centre of the circular residual resistant section has been considered.

The 3D finite element model is composed of a type of elements called C3D20, in accordance with the ABAQUS/Standard nomenclature (20 node quadratic brick). The final number of elements is 41664 . The mesh density of this model has been considerably increased in the area close to the cracked section of the shaft (Figure 14) in order to obtain more accurate estimates of stresses and strains caused by the external loads that have been applied to the model. In order to simulate the effect of the weight, a vertical load, F, and a bending moment, M, have been located at the end of the shaft, and a distributed load, PL, has been applied across the length as can be seen in Figure 13 (b).

The crack has been simulated considering two parts joined by means of the interaction 'Tie', in accordance with the ABAQUS nomenclature, between the surfaces that constitute the unbroken part of the cracked section. A surface-to-surface contact interaction has been defined for the cracked area, in order to avoid the interpenetration between the crack faces when the crack is closed. The interaction properties that have been selected to complete the definition of the contact are 'hard contact' (in accordance with the ABAQUS nomenclature) as normal behaviour, which does not allow the penetration between the crack faces and prevents the transfer of tensile stresses across the interface, and 'rough friction' (in accordance with the ABAQUS nomenclature) as tangential behaviour, which means an infinite coefficient of friction, avoiding all relative sliding motion between two contacting surfaces.
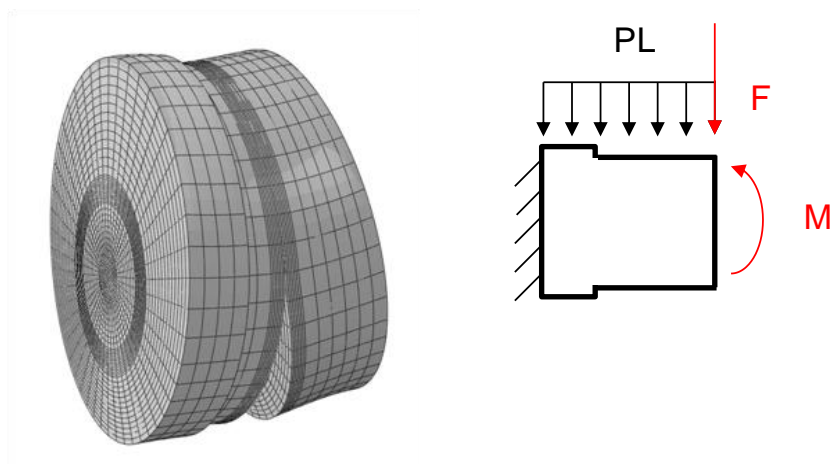

Figure 13. a) Detail of the 3D finite element model of a short part of the shaft that contains the cracked section (angular position $180^{\circ}$ ) b) Loads locations

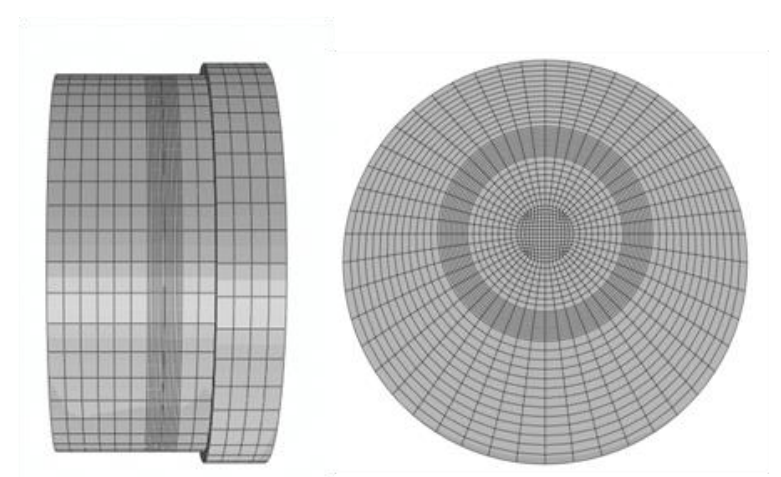

Figure 14. Lateral and front views of the model of the cracked section (reference angular position, $\left.0^{\circ}\right)$

In the model configuration illustrated in Figure 14, the angular position of the shaft is such that the vertical axis is a symmetry axis of the crack, while the maximum depth of the annular crack is located in the bottom area of the cross-section. This angular position of both shaft and crack has been assumed as reference configuration (rotation) of the system.

The degrees of freedom associated with the nodes located on the left side of the model have been constrained while the bending moment and shear forces, previously evaluated with the preliminary model, at the cross-section B, have been applied to the right side of the 3D FE model, in the vertical diametrical plane. Also, the gravity effect has been considered.

Then, the stress and strain distributions caused by gravity and the above mentioned external loads have been evaluated. Owing to the model characteristics, it has been possible to evaluate the area of the opposite surfaces of the crack that are virtually affected by axial tensile stresses that cause this part of the crack to be open. The open area of the crack is coloured dark blue in Figure 15a. The cracked area coloured grey is the residual resistant section, while the remaining part of the crack surface, plotted with multi-colours, is affected by contacts with the opposite surface of the crack, caused by axial compressive stresses and corresponding displacements. 


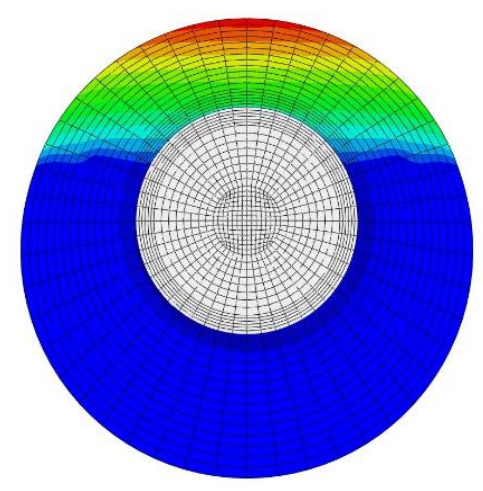

a)

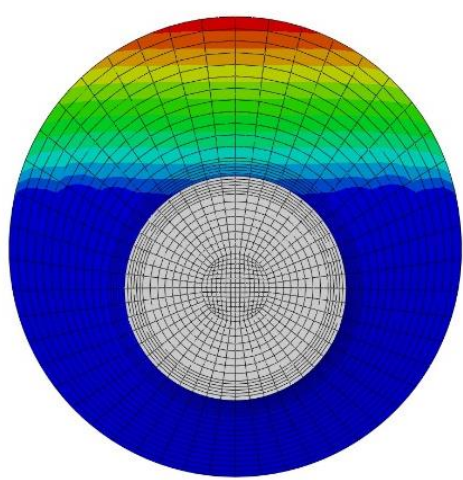

b)

Figure 15. Crack closure evaluated for the angular position of $0^{\circ}$ degree, a) and $180^{\circ}$ degree, b)

Based on these results it is possible to evaluate the area and centroid of the actual resistant section, $\mathrm{A}_{\mathrm{r}}$, that is the part of the cracked section composed of both the residual resistant section and the part of the crack surface subjected to compressive stresses. Besides, it is possible to evaluate the angular position of the principal axes, $x^{\prime}$ and $y^{\prime}$, of the actual resistant section, with respect to the horizontal reference axis, $x$, and the corresponding second moments of area. In the end, the inclination angle between the neutral axis and the horizontal reference axis can be obtained. Figure $15 \mathrm{~b}$ shows the crack closure evaluated by rotating the shaft $180^{\circ}$ degrees.

Afterwards, the above-mentioned parameters have been evaluated for different angular positions of the shaft, from $0^{\circ}$ degrees to $360^{\circ}$ degrees, by assigning a constant increment of $15^{\circ}$ degrees to the shaft rotation, $\theta$.

In order to use the same 3D finite element model, the equivalent effects caused by the changes in the shaft angular position have been obtained by rotating the diametrical plane that contains the gravity force and all the above mentioned external forces applied to the right side of the model.

This investigation has allowed the periodic changes in the area of the actual resistant section to be evaluated over a full revolution of the shaft. These changes are just a consequence of the breathing mechanism of the crack. In order to obtain a dimensionless parameter, the area $A_{r}$ has been divided by the area of the original unbroken cross-section of the shaft, $\mathrm{A}_{\mathrm{o}}$ :

$$
\Lambda=\frac{\mathrm{A}_{\mathrm{r}}}{\mathrm{A}_{\mathrm{o}}}
$$

Figure 16 shows the parameter $\Lambda$ as a function of the shaft rotation. The order analysis of the function $\Lambda(\theta)$ has been carried out. Table shows the mean value and the amplitude of the first five harmonic orders of the parameter $\Lambda$. The dimensionless area of the circular residual resistant section is 0.2349 . Therefore, the closed part of the cracked section can give an average contribution to the area of the actual resistant section that is nearly the same of that of residual resistant section. Moreover, the amplitude of the first harmonic order of the parameter $\Lambda$ gives the most important contribution to the changes in the area of the actual resistant section.

For a given rotation of the shaft, the dimensionless area of the actual resistant section can be subdivided into the area $\Lambda_{\mathrm{c}}$, subjected to compressive stresses, and the area $\Lambda_{\mathrm{t}}$, subjected to tensile stresses. Figure 17 shows the dimensionless parameters $\Lambda_{\mathrm{c}}$ and $\Lambda_{\mathrm{t}}$ as a function of the shaft rotation. Figure 16 and Figure 17 show that, as a result of the annular shape of the crack, the damaged cross-section of the rotor is able to transmit compressive stresses mainly through the closed part of the crack surface whose extension is affected by the breathing mechanism. Therefore, for any angular position of the shaft, the tensile axial stresses are mainly transmitted only by the residual resistant section of the cracked section. This breathing mechanism is quite different from that of common shaft transverse cracks having an elliptical front [1],[10],[11]. 


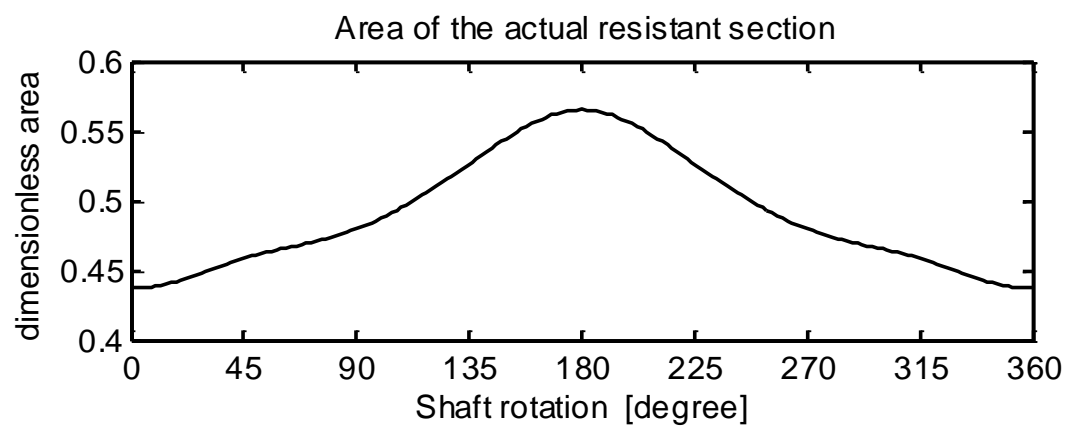

Figure 16. Effects of the shaft rotation on the area of the actual resistant section

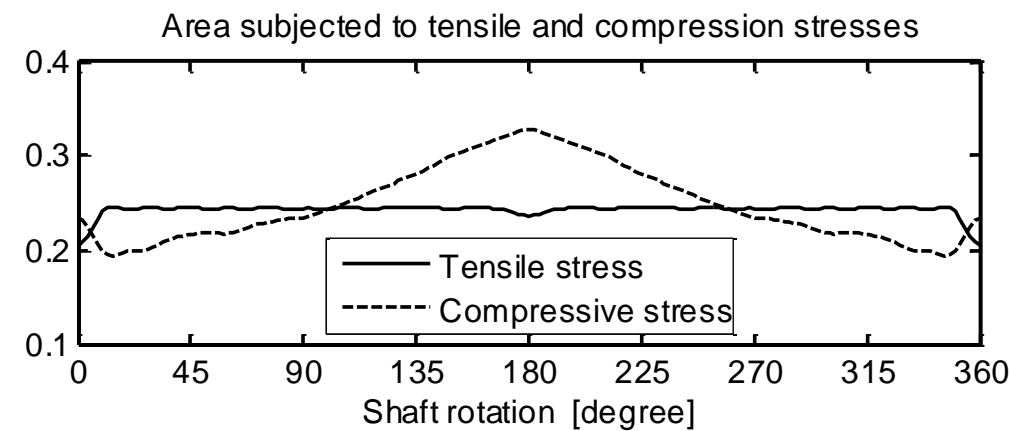

Figure 17. Effects of the shaft rotation on the area of the two parts of the actual resistant section subjected to tensile stresses and compressive stresses

Table 2. Order analysis of the dimensionless area of the actual resistant section

\begin{tabular}{|c|c|}
\hline $\begin{array}{c}\text { HARMONIC } \\
\text { ORDER }\end{array}$ & $\Lambda$ \\
\hline Mean Value & 0.49151 \\
\hline $1 \mathrm{X}$ & 0.05601 \\
\hline $2 \mathrm{X}$ & 0.01058 \\
\hline $3 \mathrm{X}$ & 0.00710 \\
\hline $4 \mathrm{X}$ & 0.00103 \\
\hline $5 \mathrm{X}$ & 0.00098 \\
\hline
\end{tabular}

The aforementioned investigation has also allowed the periodic changes in the second moments of area of the actual resistant section of the shaft to be evaluated with respect to the corresponding principal axes. The same study has provided the estimate of the periodic changes in the angular position of the principal axes, $x$ ' and $y^{\prime}$, of the actual resistant section, with respect to the horizontal reference axis, $x$. Based on the results of this investigation, the breathing of the transverse crack caused by the rotor weight over a complete rotation of the shaft has been determined.

Figure 18 shows the parts of the cracked section that can transmit tensile and compressive axial stresses, as well as the open crack, evaluated for six different rotations of the shaft. In Figure 18 the open part of the crack is plotted with a white background while the parts of the cracked section that can transmit compressive and tensile axial stresses are plotted with different shades of grey. The principal axes, $x^{\prime}$ and $y^{\prime}$, of the actual resistant section obtained for each angular position of the shaft are also shown. 

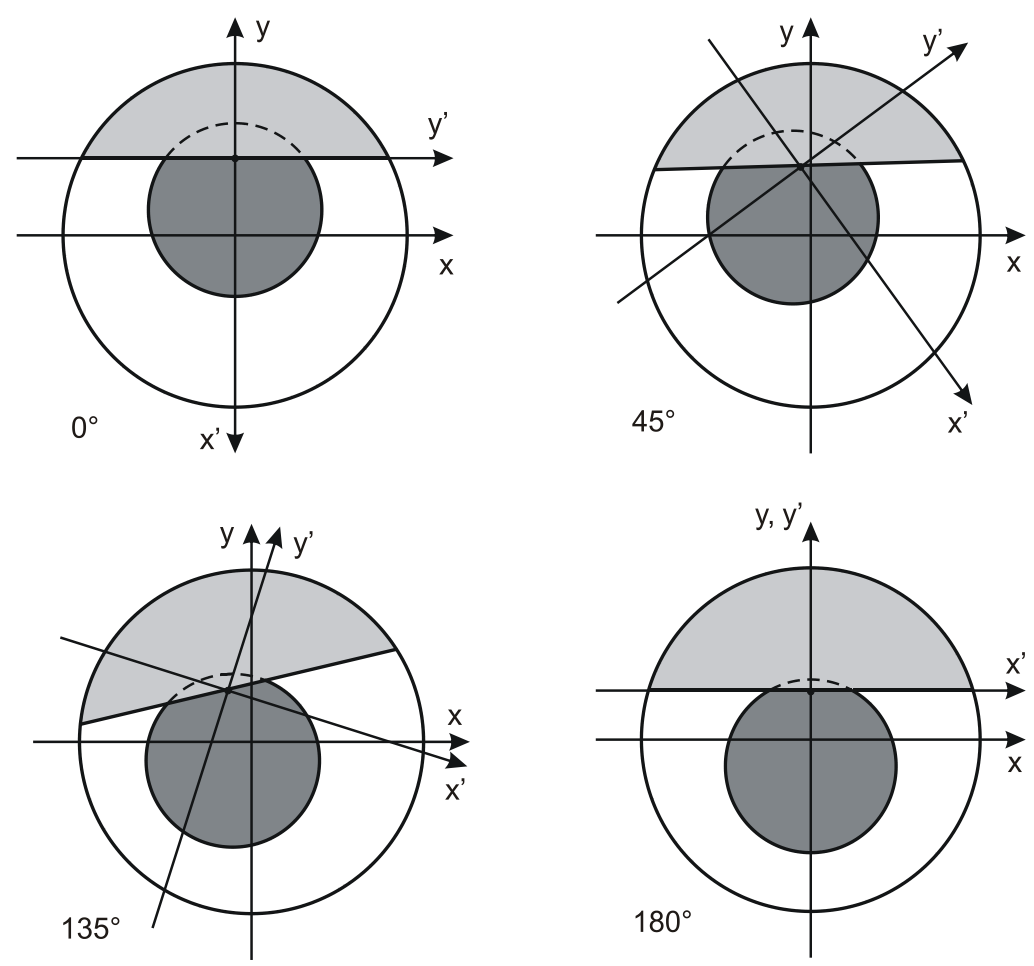

Compressive stresses
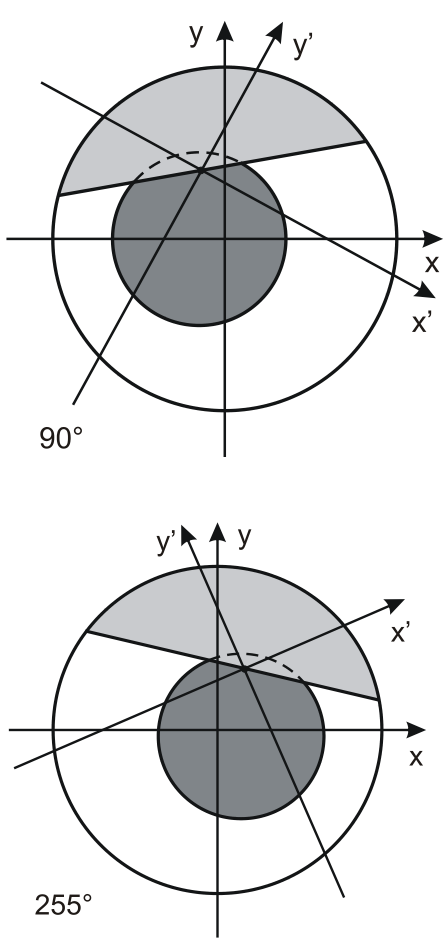

Open crack

Figure 18. Crack breathing evaluated for six angular positions of the shaft

Contrary to the crack breathing phenomenon that affects common shaft transverse cracks having an elliptical front, in the present case study the crack never closes completely over an entire revolution of the shaft. Conversely, because of the annular shape of the crack, the area of the crack surfaces that is subjected to compressive stresses is lightly influenced by the shaft rotation.

In order to obtain dimensionless parameters, the second moments of area of the actual resistant section, evaluated with respect to the corresponding principal axes, have been divided by the second moment of area of the original unbroken section of the shaft. These dimensionless second moments of area have been denoted $\mathbf{J}_{\mathrm{x}^{\prime}}$ and $\mathrm{J}_{\mathrm{y}^{\prime}}$. Figure 19 shows the periodic changes in the normalized second moments of area $\mathbf{J}_{\mathrm{x}^{\prime}}$ and $\mathrm{J}_{\mathrm{y}}$, evaluated over a full revolution of the shaft.

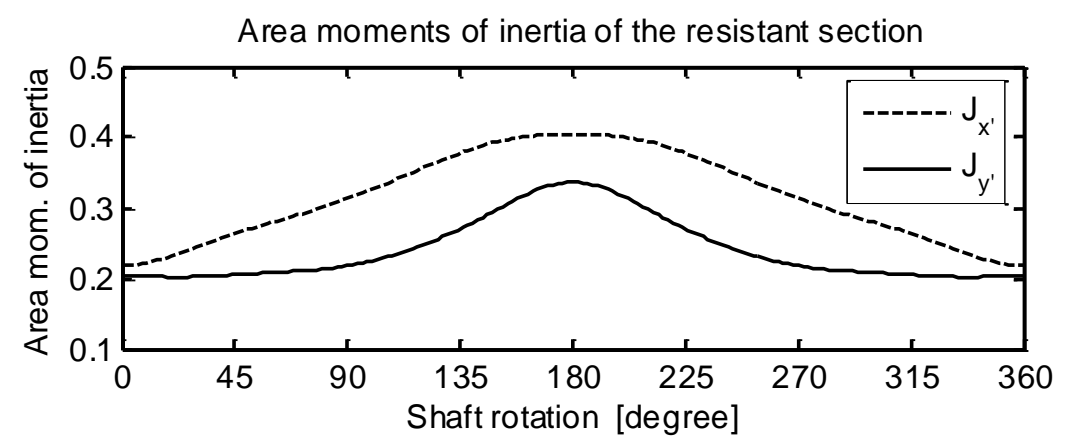

Figure 19. Effect of the shaft rotation on the second moments of area of the actual resistant section evaluated with respect to the principal axes $\left(x^{\prime}, y^{\prime}\right)$

The order analysis of the second moments of area $\mathrm{J}_{\mathrm{x}^{\prime}}$ and $\mathrm{J}_{\mathrm{y}^{\prime}}$ has been then carried out. Table 3 shows the mean value and the amplitude of the first five harmonic orders of the parameters $\mathbf{J}_{\mathrm{x}}$, and $\mathbf{J}_{\mathrm{y}^{\prime}}$. The harmonic content of the second moments of area is dominated by the contribution of the first order component. The mean value of the dimensionless second moments of area is rather low since a large part of the crack always remains open over a full revolution of the shaft. This causes a considerable decrease of the local flexural stiffness of the shaft in the area close to the cracked section in comparison to that of the unbroken cross- 
section. However, the low values of the harmonic orders of the second moments of area $\mathbf{J}_{\mathrm{x}^{\prime}}$ and $\mathrm{J}_{\mathrm{y}}$, shown in Table 3 cause only minor effects on the turbine vibrations evaluated at the two journal bearings. These characteristics of the breathing mechanism for this particular crack may cause an dynamic behaviour of the turbine. This is confirmed by the experimental evidences.

Table 3. Order analysis of the dimensionless second moments of area

\begin{tabular}{|c|c|c|}
\cline { 2 - 3 } \multicolumn{1}{c|}{} & \multicolumn{2}{c|}{ SECOND MOMENTS OF AREA } \\
\hline $\begin{array}{c}\text { HARMONIC } \\
\text { ORDER }\end{array}$ & $\mathbf{J}_{\mathrm{x}}$, & $\mathbf{J}_{\mathrm{y}^{\prime}}$ \\
\hline Mean Value & 0.31687 & 0.24092 \\
\hline $1 \mathrm{X}$ & 0.08694 & 0.05620 \\
\hline $2 \mathrm{X}$ & 0.00008 & 0.02464 \\
\hline $3 \mathrm{X}$ & 0.00549 & 0.00919 \\
\hline $4 \mathrm{X}$ & 0.00424 & 0.00297 \\
\hline $5 \mathrm{X}$ & 0.00072 & 0.00106 \\
\hline
\end{tabular}

In fact, during a machine runup, when the rotational speed crossed the first balance resonance the maximum amplitude of the $1 \mathrm{X}$ vibration reached only $22 \mu \mathrm{m}$ pp. At the end of the runup, the $1 \mathrm{X}$ vibration level measured at $3000 \mathrm{rpm}$ was $50 \mu \mathrm{m}$ pp. These low amplitudes of the $1 \mathrm{X}$ vibration indicate that, during the runup, the breathing of the crack only caused minor effects on the turbine dynamic behaviour.

Besides, by considering the high depth of the crack and the very small area of the residual resistant section, the amplitude of the $2 \mathrm{X}$ vibration, as well as that of higher harmonic orders, was quite negligible. Essentially, the dynamic effects caused by the breathing of this annular crack were rather limited.

Conversely, the sensitivity of the machine vibration to the thermal transients of the turbine shaft was considerable [16],[18], especially with regard to the $1 \mathrm{X}$ harmonic order, as a consequence of the annular shape and the large area of the crack surfaces. At the beginning of the rotor heating the compressive stresses that affect the outer part of the cross-section tend to close the crack. This causes an increase of the local flexural stiffness of the shaft. Conversely, when the temperature of the shaft core increases and the temperature distribution of the cross-section tends to become homogeneous, the outer part of the crack is subjected to a continuous opening. This causes a decrease of the local flexural stiffness of the shaft [16],[18]. The mechanical stresses generated by the non-periodic breathing mechanism of a shaft transverse crack caused by a machine heating has been analyzed in detail in [18], by the authors, also with a mathematical model.

Therefore, the breathing of the crack caused by the rotor weight, over a full revolution of the shaft, causes minor changes in the $1 \mathrm{X}$ and $2 \mathrm{X}$ harmonic components of the turbine vibration. The non-periodic breathing of the crack caused by a turbine heating causes more important slow changes in the amplitude of the shaft vibration. However, because of the particular shape of this crack, the breathing mechanism that occurs in the on-load operating condition mainly affects the synchronous harmonic component while the changes in the $2 \mathrm{X}$ vibration are really negligible. This dynamic behaviour of cracked shafts may make it rather difficult to detect the presence of the fault at the initial stage of its development.

Figure 20 shows the distribution of the axial stresses evaluated along the diametrical vertical axis, at the cracked section, for the two angular positions of the shaft of $0^{\circ}$ degrees and $180^{\circ}$ degrees, respectively. The nonlinear effects mainly affect the tensile stresses evaluated in the lower part of the circular residual resistant section. 


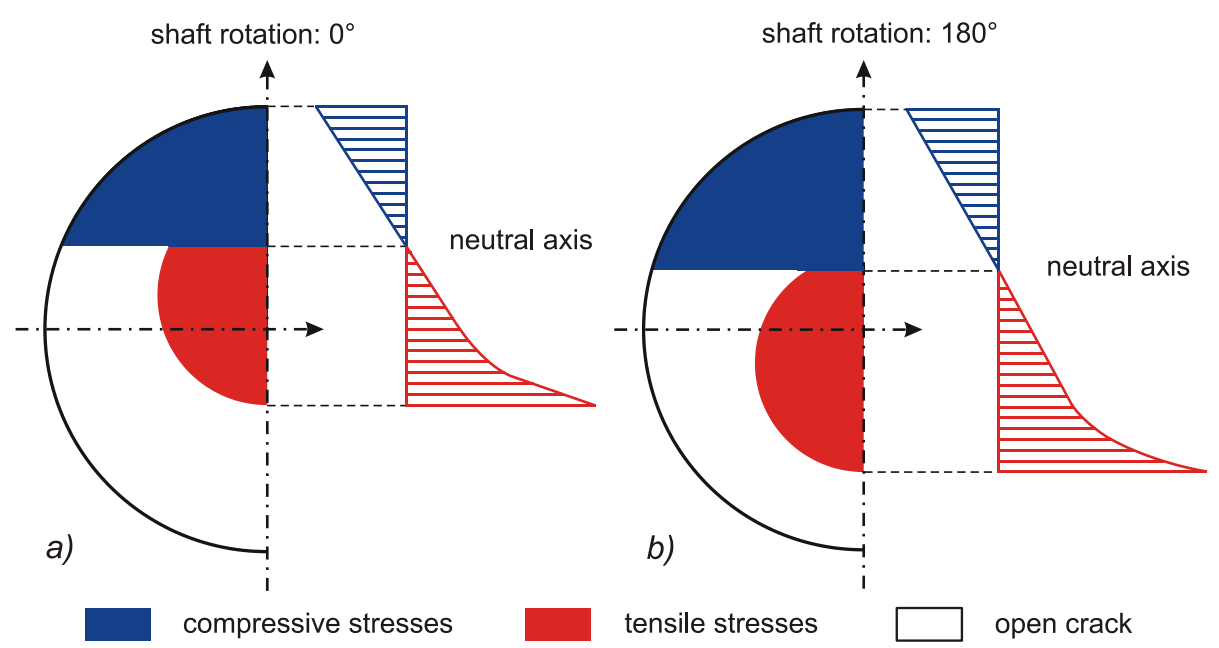

Figure 20. Distribution of the axial stresses evaluated along the diametrical vertical axis, at the cracked section, for the angular positions of the shaft of $0^{\circ}$ degrees, a), and $180^{\circ}$ degrees, $b$ )

During the inspection in the workshop, before removing the blades of the HP stages the eccentricity of the shaft was measured with dial gauges mounted, in the vertical radial direction, at nine cross-sections along the whole longitudinal axis of the rotor.

Multiple readings of the dial gauges were collected changing the angular position of the shaft, with an angular step of $45^{\circ}$ degrees, over a complete turbine revolution. In case of uncracked rotors and an ideal null geometrical runout, the dial gauges should give constant readings. Conversely, in the present case, the measures provided by the dial gauges depended on the shaft angular position. The maximum variation in the readings carried out at a given axial position is an estimate of the change in the local static deflection of the shaft caused by the crack breathing induced by the rotor weight. The maximum variations in the shaft deflection measured along the turbine are shown in Figure 21. The magnitude of these changes depends considerably on the axial position of the measurement point. The maximum change in the shaft static deflection has been detected in an area very close to the cracked section. The experimental readings collected for the cracked section, over a complete revolution of the shaft (every $45^{\circ}$ degrees), are shown later on (Figure 22)

The readings provided by the dial gauges might be affected by a not null geometrical runout of the shaft. However, because of the high values of the maximum variations of the readings provided by the sensors mounted near the HP stages, it has been assumed that the runout error can only give a minor contribution to the eccentricity measurements.

The results of this test, obtained for a given cross-section, have provided an estimate of the changes in the shaft static deflection caused by the crack breathing phenomenon that occurs over a full revolution of the rotor.
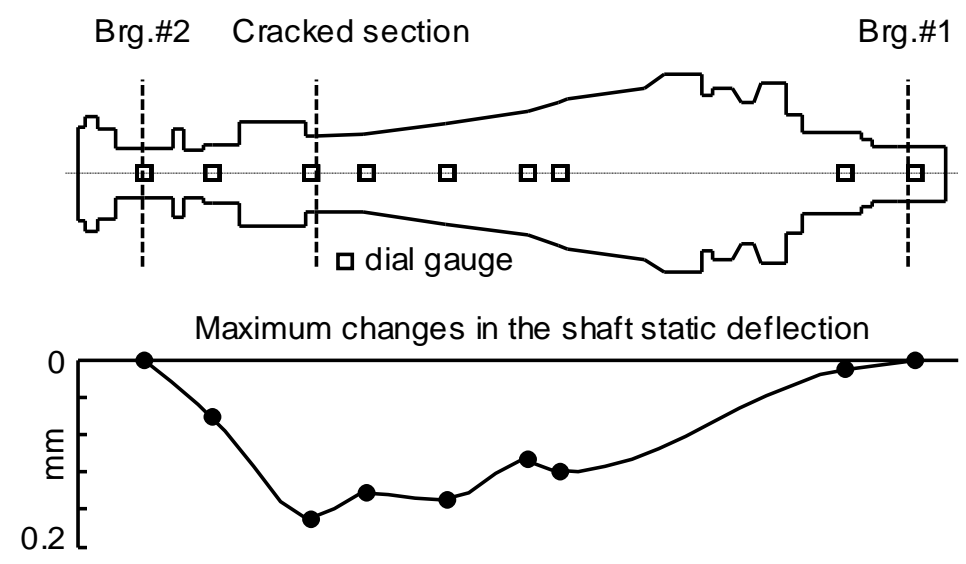

Figure 21. Maximum changes in the static deflection of the shaft, caused by the crack breathing, experienced over a full revolution of the turbine rotor 


\section{RESULT VALIDATION}

In order to validate the results provided by the model-based study of the crack breathing, the values of the second moments of area of the cracked section evaluated over a full revolution of the shaft, by means of the 3D finite element model, have been included in the finite element model of the turbine rotor shown in Figure 12, composed of only beams finite elements. More in detail, the values of the second moments of area of the cracked section, and the corresponding inclination angle of the major principal axis, have been assigned as input data of the two beam finite elements of the mesh that are adjacent to the cracked section of the rotor. These parameters have been changed in the finite element model for any rotation of the shaft of $15^{\circ}$ degrees.

Then, the static deflection of the rotor has been evaluated for different angular positions, over a full revolution, with an angular step of $15^{\circ}$ degrees. The shaft deflection evaluated in the cross-section A-A (Figure 12), which is very close to the axial position of the crack, has been considered for a comparison between experimental data and numerical results (Figure 22). The dots in Figure 22 represent the experimental readings (every $45^{\circ}$ degrees) provided by dial gauges. The good accordance between experimental and numerical results, illustrated in Figure 22, confirms that the investigation method described in this paper for the study of the breathing mechanism of a shaft transverse annular crack can provide accurate results.

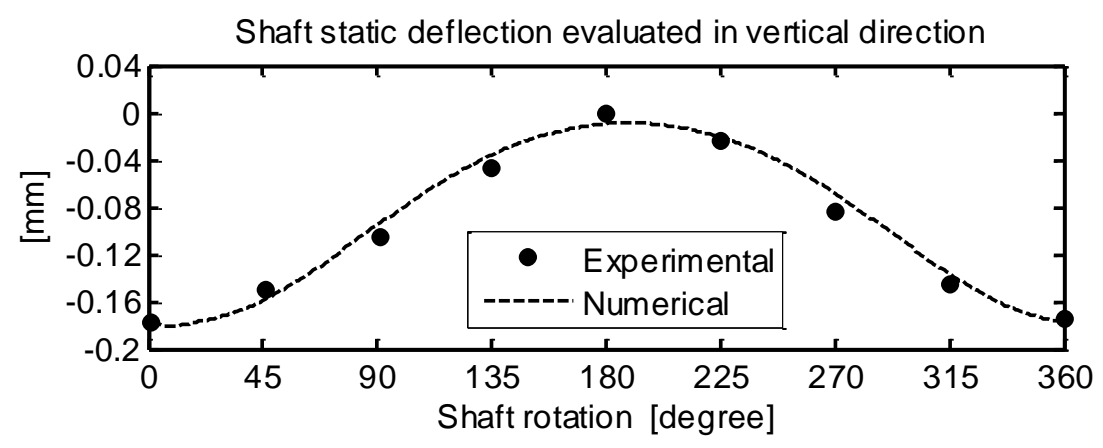

Figure 22. Effects of the shaft rotation on the turbine static deflection evaluated near the cracked section: comparison between experimental data and numerical results

\section{CONCLUSIONS}

The propagation of transverse cracks in the rotors of rotating machinery may cause sudden catastrophic damage. The early detection of this fault may be obtained by the on-line analysis of the shaft vibration. However, the magnitude of abnormal harmonic components in the frequency spectrum of the machine vibration can be significantly influenced by the crack depth and the shape of the crack front. The effects of gravity in horizontal shafts cause a periodic closing and opening of the crack that, in turn, induces changes in the local flexural stiffness of the cracked rotor. This phenomenon affects the harmonic content of the shaft vibration. Changes in the $2 \mathrm{X}$ harmonic order is a typical symptom of shaft crack propagations and are typical of semi-elliptical surface cracks.

A large number of numerical and experimental results obtained for common elliptical transverse cracks is available in literature. Conversely, this paper shows the results of an investigation on a circumferential annular crack that propagated in a steam turbine shaft as a result of high mechanical stresses caused by thermal shocks. The crack depth was very high in comparison to the rotor diameter; however, the particular shape of this crack caused a breathing mechanism that induced only small changes in the $2 \mathrm{X}$ vibration. Therefore, the early on-line detection of the fault was rather difficult.

The changes in the second moments of area of the cracked section that occur over a full revolution have been studied by means of a 3D finite element model of a short part of the rotor, close to the crack.

Then, the periodic changes in the local flexural stiffness of the shaft have been considered in a further simplified finite element model of the turbine rotor. This model has been used to simulate the periodic changes in the static deflection of the shaft, caused by gravity, over a full revolution. The experimental data have been successfully compared to the numerical results of this study. Besides, the $1 \mathrm{X}$ and $2 \mathrm{X}$ vibration data collected during a machine runup are shown in order to prove the little significance of the fault symptoms caused by this crack. 


\section{REFERENCES}

[1] Bachschmid N., Pennacchi P., Tanzi E., Cracked rotors - A survey on static and dynamic behavior including modelling and diagnosis, Springer, Berlin, Germany, (2010) ISBN 978-3-642-01485-7.

[2] Barella S., Bellongini M., Boniardi M., Cincera S., Failure Analysis of a Steam Turbine Rotor, Engineering Failure Analysis, 18 (2011) 1511-1519.

[3] Ishida Y., Cracked Rotors: Industrial Machine Case Histories and Nonlinear Effects Shown by Simple Jeffcott Rotor, Mechanical Systems and Signal Processing, 22(4) (2008) 805-817.

[4] Sekhar, A.S., Multiple cracks effects and identification, Mechanical Systems and Signal Processing, 22 (4) (2008) 845-878.

[5] Andrieux S., Varé C., 3D cracked beam model with unilateral contact. Application to rotors, European Journal of Mechanics A/Solids 21 (2002) 793-810.

[6] Papadopulos C.A., Some comments on the calculation of the local flexibility of cracked shafts, Journal of Sound and Vibration, 278 (4-5) (2004) 1205-1211.

[7] Sinou J.-J., Detection of cracks in rotor based on the $2 \times$ and $3 \times$ super-harmonic frequency components and the crack-unbalance interactions, Communications in Nonlinear Science and Numerical Simulation, 13 (9) (2008) 2024-2040.

[8] Darpe A.K., Gupta K., Chawla A., Coupled bending, longitudinal and torsional vibrations of a cracked rotor, Journal of Sound and Vibration, 269 (2004) 33-60.

[9] Wu X., Friswell M.I., Sawicki J.T., Finite element analysis of coupled lateral and torsional vibrations of a rotor with multiple cracks, Proc. of ASME Turbo Expo Gas Turbine Technology: Focus for the Future, 2005, June, Vol. 4, 41-850.

[10] Chondros T.G., Dimarogonas A.D., Yao J., Vibration of a Beam with a Breathing Crack, Journal of Sound and Vibration 239 (1) (2001) 57-67.

[11] Patel T.H., Darpe A.K., Influence of crack breathing model on nonlinear dynamics of a cracked rotor, Journal of Sound and Vibration, 311 (3-5) (2008) 953-972

[12] Yadavar Nikravesh M., Meidan Sharafi M., Failure of a steam turbine rotor due to circumferential crack growth influenced by temperature and steady torsion, Engineering Failure Analysis, 66 (2016) 296-311.

[13] Vaziri, A., Nayeb-Hashemi, H., The effect of crack surface interaction on the stress intensity factor in Mode III crack growth in round shafts, Engineering Fracture Mechanics 72 (4) (2005) 617-629.

[14] A. Vania, P. Pennacchi, S. Chatterton, A Parametric Analysis of the Breathing Phenomenon for different shapes of shaft cracks, Proc. of ISMA 2012, Int. Conf. on Noise and Vibration Engineering, Sept. 2012, Leuven, Belgium, ID 119.

[15] A. Vania, P. Pennacchi, S. Chatterton, Supersynchronous Vibrations Caused by Transverse Annular Cracks in Rotating Machines, Proc. of the 6th Int. Conf. on Acoustical and Vibratory Surveillance Methods and Diagnostic Techniques, Compiègne, France, October 25-26, (2011), pp. 1-13

[16] Vania A., Pennacchi P., Shaft crack detection in a steam turbine: experimental evidences and model-based investigations, Proc. of ISMA 2010, Int. Conf. on Noise and Vibration Engineering, Sept. 2010, Leuven, Belgium.

[17] Bachschmid N., Vania A., Crack detection in a steam turbine: a case history, Proc. of the 8th IFToMM Int. Conf. on Rotor Dynamics, 2010 Sept. 12-15, Seoul, Korea, (2010), pp. 296-303

[18] Vania A., Pennacchi P., Chatterton S., Effects of Thermal Transients on Cracked Shaft Vibrations, Proc. of ASME Turbo Expo 2011, GT2011, June 6-10, (2011), Vancouver, Canada, GT2011-46181, pp. 1-8.

[19] Lalanne M., Ferraris G., Rotordynamics Predictions in Engineering, (1998), John Wiley \& Sons Inc., Chichester, England

[20] Adams M., Rotating machinery vibration, (2001), Marcel Dekker Inc., New York, N.Y., USA 